\title{
Economic Integration and the Evolution of Trade: A Geometric Interpretation of Trade Measures
}

\author{
Abdul K.M. Azhar \\ Universiti Putra Malaysia \\ Robert J.R. Elliott \\ University of Manchester
}

\begin{abstract}
The increase in global trade and the ongoing erosion of trade barriers makes the analysis of trade patterns one of the key areas in international economics. Much of the post-war expansion of trade took the form of intra-industry trade (IIT). This paper presents a simple geometric tool to analyse trade patterns specifically inter and intra-industry trade and the compatibility between levels and measures of IIT. The applicability our methodology is demonstrated using the UKs trade experience during the critical period of EU integration 1988-1997.
\end{abstract}

- JEL Classification: F19

- Key words: globalisation, international trade, intra-industry trade

\section{Introduction}

Recent decades have witnessed a proliferation of regional economic areas such as the European Union (EU), the North American Free Trade Area (NAFTA) and the Association of South East Asian Nations (ASEAN) as well as increased globalisation as evidenced by soaring levels of trade and foreign direct investment. One consequence of closer integration is the ongoing erosion of trade barriers that makes the evolution of trade patterns a key area of international economics. One

\footnotetext{
*Corresponding author: Robert J.R. Elliott, Department of Economics, University of Birmingham, Edgbaston, B151 2TT, UK, Tel: +44(0121) 414 7700, E-mail: r.j.elloitt@bham.ac.uk (C)2004-Center for International Economics, Sejong Institution, All Rights Reserved.
} 
important development is that much of the post-war expansion of trade has taken the form of intra-industry trade, commonly defined as the simultaneous imports and exports of goods from the same industry.

The seminal studies of intra-industry trade (IIT) by Balassa (1966) and Grubel and Lloyd (1975) were exclusively empirical. The existence of IIT seemed to be at odds with the prevailing Heckscher-Ohlin-Samuelson (HOS) theory of comparative advantage and ushered in the development of the new trade theory. Krugman (1979) and Lancaster (1980) among others explained IIT between similarly endowed economies within a monopolistically competitive framework, while Falvey (1981) and Davis (1995) showed that IIT could also be explained within a HOS framework. A long lineage of empirical work, including Helpman (1987), Greenaway et. al. (1995), Hummels and Levinsohn (1995) and Bernhofen (1999) employ a share measure of IIT (usually the unweighted Grubel and Lloyd index) as the dependent variable in tests for the determinants of this growing phenomenon. The abundance of at best loosely related empirical and theoretical work has created a rather fuzzy set of conclusions concerning the determinants of IIT. It is possible that some of the ambiguity in the empirical evidence may be due to a number of idiosyncrasies that exist with the measurement of static IIT and its use as a dependant variable. ${ }^{1}$

Since it is pivotal to many existing empirical studies in this paper we give special attention to the properties of the Grubel and Lloyd (GL) index and concentrates on providing an evaluation of the index, in particular we highlight the possibility and number of cases where the GL index increases (deceases) while the value of IIT decreases (increases) as well as identifying "regions" that capture all trade changes in addition to the GL index. Our approach in this paper is to extend the methodology of Azhar et al. (1998) and apply trade data from the UK to different trade related scenarios.

Section I of this paper summarises the industry trade box methodology (Azhar et al. 1998) for analysing the components of trade patterns where total-trade, net trade (or inter industry trade), IIT and the Grubel and Lloyd (GL) index are calculated from a combination of import and export values with emphasis given to the characteristics and behaviour of the GL index. In Section II we provide examples

${ }^{1}$ One relatively recent development that sheds some light on the behaviour of the GL index is the measurement of dynamic or marginal intra-industry trade (MIIT) initiated by Hamilton and Kniest (1991). This spawned the creation of a number of alternative measures of MIIT by Greenaway et. al. (1994), Brülhart (1994), Dixon and Menon (1997), Azhar and Elliott (2003) as well as studies of industrial specialisation and adjustment employing these measures in Brülhart and Hine (1999). 
of how the methodology can be productively employed using data for UK trade during the critical period of EU integration, 1988-1997. Section III concludes.

\section{Components of International Trade and the Industry Trade Box}

Consider the components of international trade flows, namely exports $(X)$, imports $(M)$ from which we can calculate total trade (TT), net trade (NT), intraindustry trade (IIT) and the Grubel and Lloyd (GL) index where the latter is calculated as, ${ }^{2}$

$$
G L=\frac{(X+M)-|X-M|}{(X+M)}
$$

Since exports and imports must always be greater than or equal to zero let the trade flows for industry $i$, consists of the set of all $X$ and $M$ values for $n$ years. i.e. and $N=\{1,2,3, \ldots . n\}$ and $\forall t \in N, X_{t}, M_{t}, T T_{t}, N T_{t}, I I T_{t}, G L_{t} \geq 0 .^{3}$

A geometric space (an industry trade box) can be constructed that is equivalent to the first quadrant of a Cartesian co-ordinate plane where all trade components are positive. The static relationships between the six components can be summarised as follows; first total trade values are equal when any set of coordinates $(X, M)$ share a common sum $(X+M)$ i.e. $X+M=T T=N T+I I T$; second, net trade vales are equal when any set of co-ordinates $(X, M)$ share a common value in $|X-M|$; third, values of IIT are equal when any set of co-ordinates $(X, M)$ share a common value in $(X+M)-|X-M|$; finally, the GL index measures the share of IIT in TT consists of that set of co-ordinates $(X, M)$ that share a common value in $(X+M)-|X-M| /(X+M)$. The dimensions of the industry trade box are set to equal the maximum value of either $X$ or $M$ (which ever is the larger). This means that by construction, all possible trade points $(X, M)$ will be included within the box that will have sides equal to either or $\max \left(X_{t}\right)$ or $\max \left(M_{t}\right)$ with an area given by $D=\left[\max \left(X_{t}^{2}, M_{t}^{2}\right)\right] .{ }^{4}$ The vertical $X$-axis denotes the export values and the horizontal $M$-axis denotes the import values.

\footnotetext{
${ }^{2}$ See Greenaway and Milner (1986) and Kol (1988) for general discussion of the properties of GL index.

${ }^{3}$ The industry subscript $i$ is not included in this paper for expositional simplification. Trade values are ordinarily available at uniformly spaced time intervals, monthly, quarterly or annually. This means we are able to define exports and imports as having an initial time, denoted by $t=0$ and subsequent time periods, $t=1$, $t=2$ etc. denoted by a $t$ subscript. Hence, we are able to study the behaviour of the trade components that consist of the various functional forms of these export and import values over this discrete set of values.
} 
By construction we consider trade from the perspective of a home country and foreign country. The leading diagonal, a $45^{\circ}$ line from the origin (and the only trade components axis of symmetry), bisects the box into two equal triangles (see Figure 1) and is the locus of balanced trade where $X_{t}=M_{t}$. The two triangular planes in the box are an upper triangle containing co-ordinate points $\left(X_{t}, M_{t}\right)$ where, $X_{\mathrm{t}}>M_{t}$ defined as the net exporter $(N E)$ plane and co-ordinate points $\left(X_{t}, M_{t}\right)$ where $M_{t}>X_{t}$ in the lower triangle, defined as the net importer $(N I)$ plane. Along this $X_{t}=M_{t}$ line, the conditions are such that $T T$ equals IIT, GL equals unity, and NT equal zero.

For any particular year, each of the four components, $T T, N T$, IIT and $G L$ are contained within a single trade point $\left(X_{t}, M_{t}\right)$. If a trade box includes a number of years data we will have a set of points with values for each component for each year so we can determine the locus of each respective trade component. The first three are relatively straightforward, however, the locus of GL index values is worth considering in more detail. ${ }^{5}$

Figure 1 plots the locus of points where trade components are equal, labelled

Figure 1. Industry Trade Box

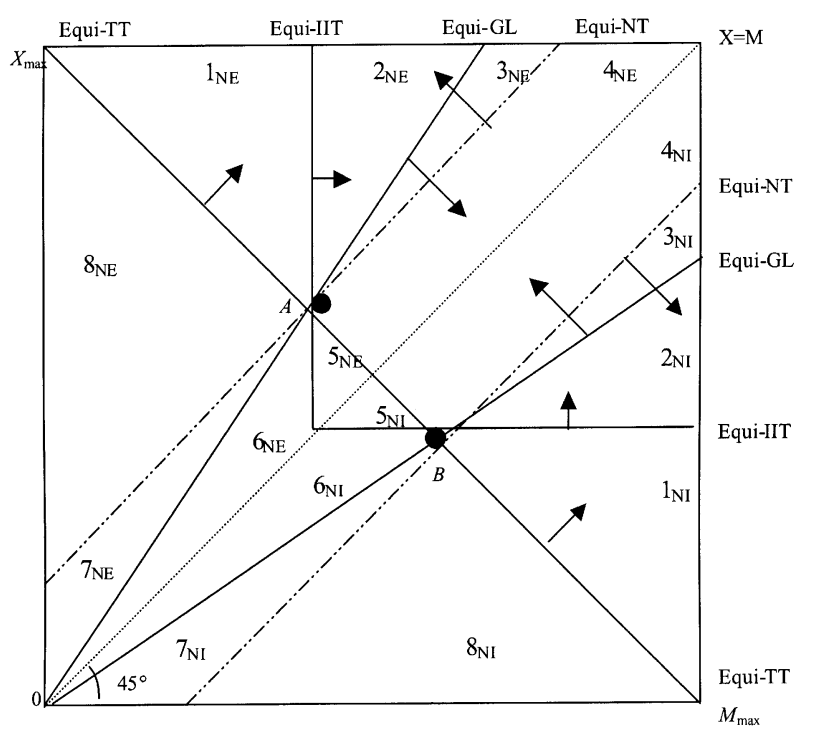

\footnotetext{
${ }^{4} \mathrm{~A}$ trade box is defined at all levels of aggregation such as country, region, sector, industry or product. In practice we refer to an industry trade box as this is where this methodology is most usefully applied. All values of exports and imports must be deflated so all values are in constant prices.

${ }^{5}$ In general the locus of the trade components in the trade box is the straight line containing all the points whose co-ordinates satisfy the equation $a X+b M+c=0$ where $a, b$, and $c$ are real, and $a$ and $b$ are not both equal to zero.
} 
Figure 2. GL Isoclines

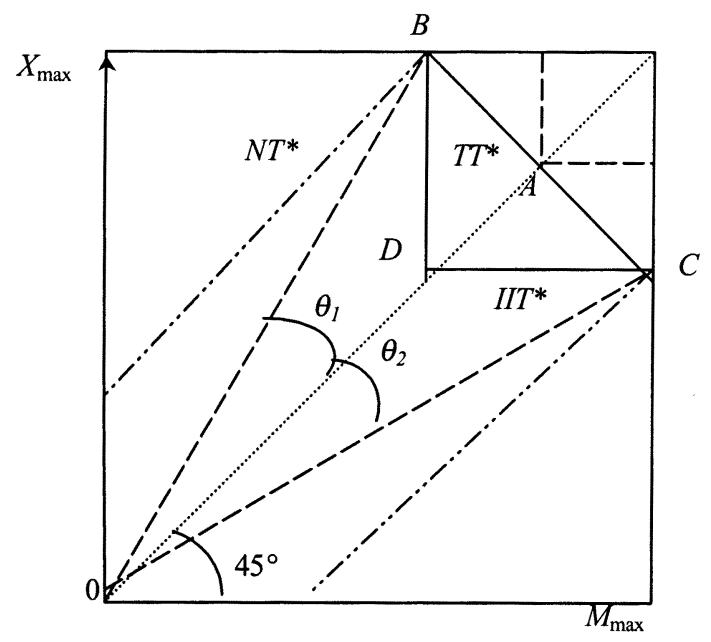

equi-TT, equi-NT, equi-IIT and equi-GL. The arrows show the direction of increasing values of each component from the standpoint of two hypothetical points A and B. Each region is numbered (sixteen altogether, eight in each of the $\mathrm{NI}$ and NE planes) where each region reflects a different combination of changes in TT, NT, IIT and the GL index.

One relationship worth considering in more detail is the joint behaviour of the GL index and the absolute level IIT value. First we derive the properties of the GL index within the confines of the trade box. Consider a hypothetical trade box in Figure 2.

Consider rays $\mathrm{OB}$ and $\mathrm{OC}$ subtending equi-angles $\theta_{1}, \theta_{2}$ from the main diagonal. Suppose that $A, B, C$, and $D$ are trade points in the trade space. $A, B$ and $C$ share equal total trade values, on the $T T^{*}$ line, and $B, C$, and $D$ share equal $I I T$ values, on the $I I T^{*}$ line. $O A^{*}=T T^{*}$, and $T T^{*}-I I T=N T^{*}=A B, \theta_{1}=A B / O A=T T^{*}-I I T^{*} /$ $T T^{*}=1-G L^{*}$ so $G L^{*}=1-\tan \theta_{1}$ and GL values are constant along any ray from the origin. Every point on the rays OB and OC share an equal GL value. The angle of the GL ray decreases towards a slope of unity as it sweeps from the vertical axis (line of zero imports) towards the line of balanced trade. Consider $<B O A$ in Figure 2. Since $0 \leq \theta_{1} \leq 45^{\circ}, 0 \leq \tan \theta_{1}$, as $\theta_{1}$ decreases (approaches OA) then $\tan \theta_{1}$ approaches zero and GL* approaches 1 . By similar reasoning for $<\mathrm{A} 0 \mathrm{C}$, $G L^{*}$ tends towards unity as $\theta_{2}$ decreases, that is, as the equi-GL ray sweeps from the horizontal axis (line of zero exports) towards the main diagonal.

We now outline how to detect those cases where the unadjusted GL index 
Figure 3. (a) No trade switch, (b) Trade Switch
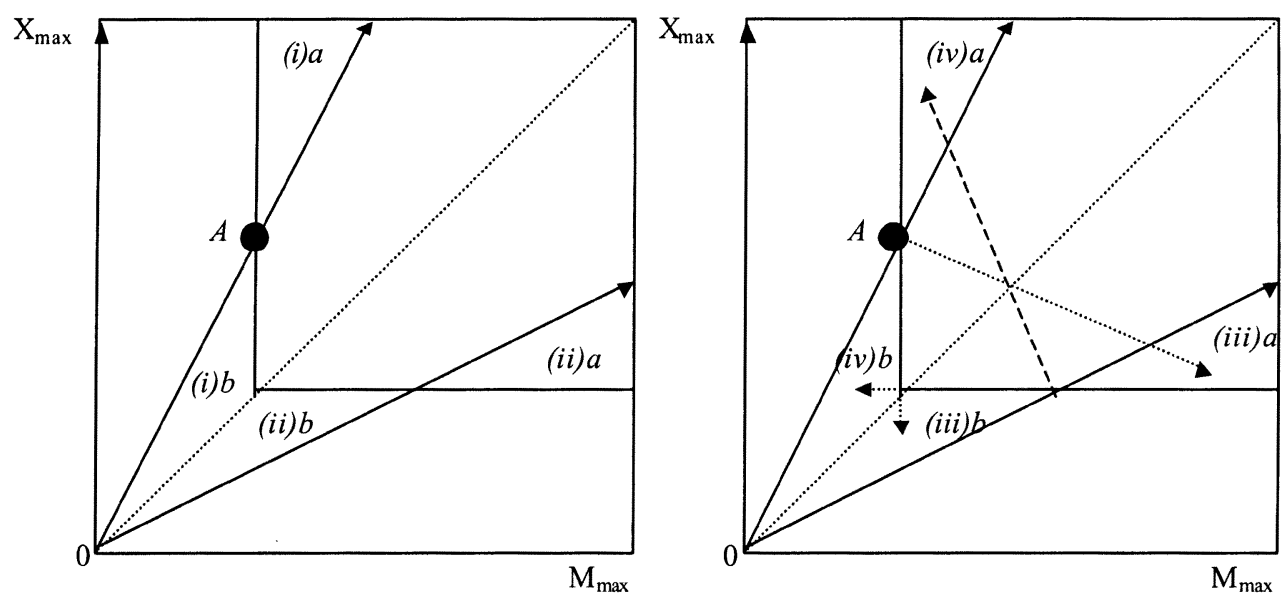

increases (decreases) while total IIT decreases (increases). In period $t$ there are four possible alternatives for a new trading equilibrium where the home country's trade possibilities for two periods is divided into four cases; (1) where the home country is a net exporter in both periods; (2) where the home country is a net importer in both periods; (3) where the home country is a net exporter in the first period and a net importer in the second period and (4) where the home country is a net importer in the first period and a net exporter in the second period. In addition each case comprises of either (a) increasing or (b) decreasing volumes of total trade. Figures $3 \mathrm{a}$ and $3 \mathrm{~b}$ demonstrate the combination of possibilities.

Figures $3 \mathrm{a}$ and $3 \mathrm{~b}$ represent possible moves in the trade position between years $t-1$ and $t$. Cases (1) and (2) are represented in Figure 3a where there is no trade switch (the home country remains either a net exporter or a net importer). Consider a move from $A$ to any point within triangle (i) $a$ or (i) $b$ (regions $2_{\mathrm{NE}}$ and $6_{\mathrm{NE}}$ from figure 1). In triangle (i) $a$ IIT has increased but the GL index has fallen. In (i) $b$ the GL index has risen but IIT has fallen. Cases (3) and (4) are considered in Figure 3b and demonstrate the effects of a change in the direction of net trade. In Figure $3 \mathrm{~b}$, a move from $A$ to triangle (iii) $a$ (region $2_{\mathrm{NI}}$ from figure 1) reflects an increase in imports coupled with an increase in absolute IIT but a corresponding fall in the GL index. The full set of possibilities is represented in Table 1 .

Table 1 demonstrates that expecting the GL index and IIT values to always move in the same direction is a simplification of the relationship. Outside these specified cases however, (four regions out of the total of sixteen from figure 1) the GL index and IIT values behave as expected. 
Table 1. GL and IIT Incompatibility Triangles

\begin{tabular}{cccccc}
\hline Case & Trade Plane & $\begin{array}{c}\text { (a) increasing } \\
\text { total trade }\end{array}$ & Region & $\begin{array}{c}\text { (b) decreasing } \\
\text { total trade }\end{array}$ & Region \\
\hline 1 & $\mathrm{NE} \rightarrow \mathrm{NE}$ & IIT $\uparrow \mathrm{GL} \downarrow$ & $2_{\mathrm{NE}}$ & IIT $\downarrow \mathrm{GL} \uparrow$ & $6_{\mathrm{NE}}$ \\
2 & $\mathrm{NI} \rightarrow \mathrm{NI}$ & IIT $\uparrow \mathrm{GL} \downarrow$ & $2_{\mathrm{NI}}$ & IIT $\downarrow \mathrm{GL} \uparrow$ & $6_{\mathrm{NI}}$ \\
3 & $\mathrm{NE} \rightarrow \mathrm{NI}$ & IIT $\uparrow \mathrm{GL} \downarrow$ & $2_{\mathrm{NE}}$ & IIT $\downarrow \mathrm{GL} \uparrow$ & $6_{\mathrm{NI}}$ \\
4 & $\mathrm{NI} \rightarrow \mathrm{NE}$ & IIT $\uparrow \mathrm{GL} \downarrow$ & $2_{\mathrm{NE}}$ & IIT $\downarrow \mathrm{GL} \uparrow$ & $6_{\mathrm{NE}}$ \\
\hline
\end{tabular}

In section III we demonstrate a number of general areas where the trade box can be gainfully employed and illustrate the magnitude of the GL/IIT problem for UK trade with the EU.

\section{An Empirical Application}

In the run-up to the 1992 Single European Market deadline there were concerns that inter-industry adjustment pressures among EU member countries would increase. This was based on a popular, but loosely defined, smooth adjustment hypothesis (SAH) according to which, high levels of IIT were indicative of relatively low trade-induced adjustment costs. Under the SAH adjustment costs arise from temporary inefficiencies when markets fail to clear instantaneously in response to changes in demand or supply conditions. In this section we examine

Table 2. UK trade with our main trading regions 1988-1997

\begin{tabular}{ccccccccccc}
\hline & \multicolumn{3}{c}{ World } & \multicolumn{2}{c}{ Europe $_{1}$} & \multicolumn{2}{c}{ USA } & \multicolumn{2}{c}{ Japan } & \multicolumn{2}{c}{ Asia $_{2}$} \\
\cline { 2 - 11 } Year & $\begin{array}{c}\text { Import } \\
(\$ \mathrm{~m})\end{array}$ & $\begin{array}{c}\text { Export } \\
(\$ \mathrm{~m})\end{array}$ & $\begin{array}{c}\text { Import } \\
(\$ \mathrm{~m})\end{array}$ & $\begin{array}{c}\text { Export } \\
(\$ \mathrm{~m})\end{array}$ & $\begin{array}{c}\text { Import } \\
(\$ \mathrm{~m})\end{array}$ & $\begin{array}{c}\text { Export } \\
(\$ \mathrm{~m})\end{array}$ & $\begin{array}{c}\text { Import } \\
(\$ \mathrm{~m})\end{array}$ & $\begin{array}{c}\text { Export } \\
(\$ \mathrm{~m})\end{array}$ & $\begin{array}{c}\text { Import } \\
(\$ \mathrm{~m})\end{array}$ & $\begin{array}{c}\text { Export } \\
(\$ \mathrm{~m})\end{array}$ \\
\hline 1988 & 223.3 & 166.2 & 131.9 & 92.2 & 20.7 & 19.7 & 13.3 & 3.5 & 32.6 & 23.5 \\
1989 & 209.5 & 161.0 & 128.9 & 90.1 & 21.2 & 19.1 & 12.1 & 3.7 & 32.2 & 22.1 \\
1990 & 223.6 & 183.8 & 135.4 & 107.7 & 22.3 & 20.8 & 11.7 & 4.4 & 32.3 & 23.6 \\
1991 & 196.9 & 170.9 & 117.1 & 104.1 & 20.5 & 16.9 & 11.0 & 3.6 & 31.0 & 21.0 \\
1992 & 199.6 & 167.9 & 119.1 & 101.7 & 19.5 & 17.2 & 11.2 & 3.3 & 32.2 & 22.0 \\
1993 & 182.2 & 157.7 & 100.2 & 88.2 & 19.9 & 19.0 & 10.4 & 3.3 & 33.1 & 24.4 \\
1994 & 200.1 & 173.4 & 115.5 & 103.9 & 22.9 & 19.8 & 11.7 & 3.7 & 36.3 & 26.6 \\
1995 & 221.4 & 193.8 & 129.9 & 120.3 & 26.2 & 20.4 & 12.6 & 4.8 & 40.0 & 30.4 \\
1996 & 233.3 & 209.9 & 137.0 & 127.2 & 26.6 & 22.8 & 11.2 & 5.2 & 40.0 & 30.3 \\
1997 & 229.3 & 211.9 & 130.0 & 122.9 & 27.9 & 25.2 & 11.7 & 5.3 & 45.7 & 33.5 \\
\hline
\end{tabular}

Source: OECD trade statistics.

${ }^{1}$ The region Europe consists of all countries included in the geographical definition of Europe.

${ }^{2}$ The region Asia consists of all countries included in the geographical definition of Asia. 
UK trade flows over the ten-year period 1988 to 1997 at various levels of disaggregation based on the Standard International Trade Classification (SITC).

The first approach is to examine the trade patterns of the UK and five of its major trading partners (total trade values in US\$ are provided in Table 2). ${ }^{6}$

Figure 4. UK trade with five regional groupings
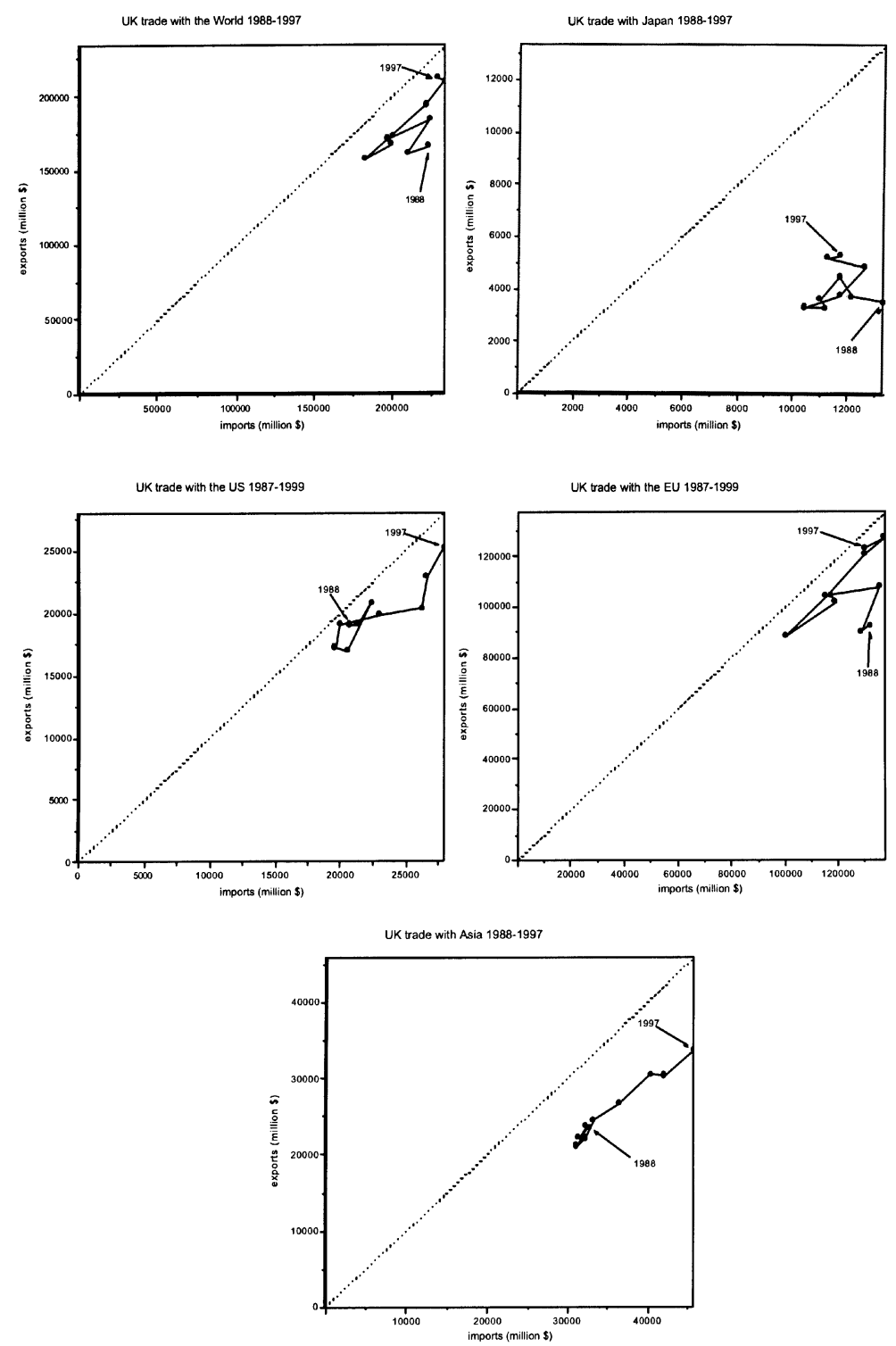

${ }^{6}$ All data are deflated to 1988 prices using GDP deflators. 
Table 2 shows that UK trade with all regions is generally increasing. Although we could calculate IIT, TT and NT separately for each trade relationship and include this information in a new table, Figure 4 demonstrates how the trade box methodology can be used to illustrate the results simply and concisely.

Figure 4 clearly illustrates that the UK is a net importer from all five regions during a period of generally increasing total trade flows. ${ }^{7}$ Closer examination, by superimposing the equi-trade component lines onto each figure, reveals that except for Japan, there appears to be at least one lengthy period where total trade increases run parallel to the leading diagonal. According to the MIIT literature (see e.g. Brülhart 1994), the symmetry of import and export increases are indicative of minimal adjustment pressures as IIT increases are coupled with constant NT values.

Additional information is supplied by a comparison of the scales of each trade box and provides a rough indication of the relative importance of UK trade with each region. UK-Asian and UK-Japanese trade, for example, are only a quarter and one tenth of UK-European trade respectively. ${ }^{8}$

However, such a broad analysis provides only one part of the story. Total bilateral trade flows may mask diverse inter- or intra-sectoral performances with the possibility of a simultaneous expansion and contraction of closely related products or industries. If for example, declining sectors happen to be highly labour intensive or the expanding sectors are highly capital intensive, the potential for significant adjustment costs, as labour takes time to retrain and re-locate, increases. This provides us with our second empirical application of the trade box.

To estimate whether the removal of non-tariff barriers as a result of the 1987 Single European Act caused increased specialisation and concentration across sectors, a cross-industry trade box can be generated. The accommodation of a number of sectors in a single box means we can represent the relative sizes of different sectors in one diagram revealing how trade induced adjustment pressures in one sector may effect the rest of the economy. ${ }^{9}$ Figure 5 represents three 1-digit

\footnotetext{
${ }^{7}$ That the UK is a net importer is not too surprising if we compare the relative GDP sizes of the UK and these larger regions. Extensions could include a bilateral trade analysis of the UK with certain politically sensitive trade partners such as individual EU countries or the Asian tigers.

${ }^{8}$ This relativity could be emphasised further by plotting all the data within a single trade box with the dimensions set by the largest trading partners maximum import or export value.

${ }^{9}$ At higher levels of disaggregation potential adjustment problems depend on the number of similar products that are in production and how important the adversely effected product compares in terms of size (trade, employment, production or geographical concentration).
} 
Figure 5. UK trade with Europe sectors SITC(6-8) 1988-1997

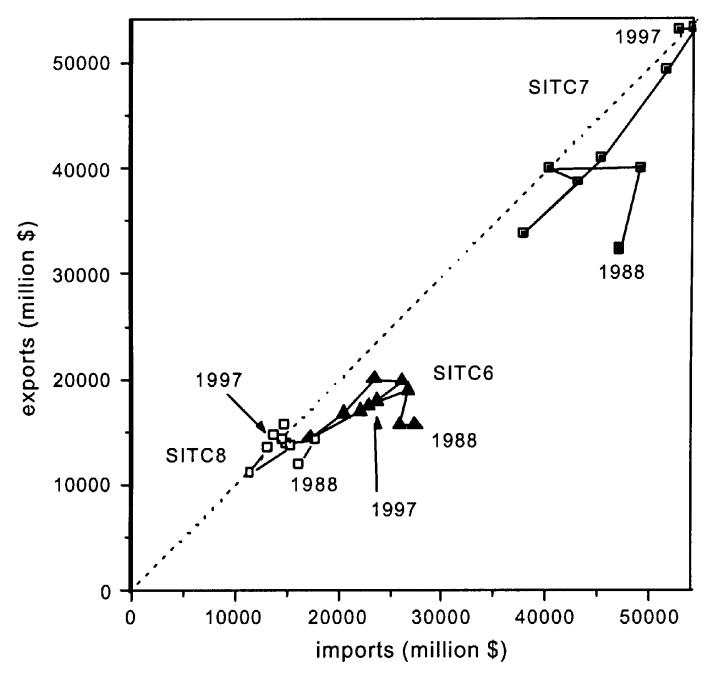

manufacturing sectors of UK-European trade. ${ }^{10}$

Clearly SITC 7 (Machinery and Transport equipment) is the largest tradable sector of the three and so changes in trade patterns in this industry are likely to impact more heavily on the UK economy than those of SITC 6 (Manufactured goods) and SITC 8 (Miscellaneous Manufactured Articles). ${ }^{11}$

Additional information can be gleaned by breaking down each 1-digit sector into its constituent SITC categories. ${ }^{12}$ The lowest 5-digit level of aggregation allows us to observe which products the UK is specialising into or out of and leads us into our third application of the trade box methodology. For UK trade with Europe Table 2 presents all trade component changes for 2831 products. A movement between any one trade-point and another, where there is at least some two-way trade, must result in a change that is picked up by one of the sixteen regions from Figure 1 (eight in the net importer and eight in the next exporter plane). Table 3 defines all possible changes and the percentage of

\footnotetext{
${ }^{10}$ For visual simplicity, Figure 5 excludes SITC 5 because of its close resemblance to SITC 8.

${ }^{11}$ The Machinery and Transport Equipment sector also tends to have significant geographical concentration so that a large adverse shift in trade patterns may exacerbate any factor reallocation problems.

${ }^{12}$ For ease of exposition the 1-digit level of aggregation is defined as a sector, the 3-digit level to be an industry and the 5-digit level to be a product. See Greenaway and Milner (1986) for further discussion.
} 
Table 3. UK trade performance with Europe 1988-1997

\begin{tabular}{clccccr}
\hline \multirow{2}{*}{ Region } & Possible Trade Changes & $\begin{array}{c}\mathrm{A} \\
\mathrm{NE} \rightarrow \mathrm{NE} \\
\%\end{array}$ & $\begin{array}{c}\mathrm{B} \\
\mathrm{NI} \rightarrow \mathrm{NI} \\
\%\end{array}$ & $\begin{array}{c}\mathrm{C} \\
\mathrm{NE} \rightarrow \mathrm{NI} \\
\%\end{array}$ & $\begin{array}{c}\mathrm{D} \\
\mathrm{NI} \rightarrow \mathrm{NE}\end{array}$ & total \\
\hline 1 & $\Delta \mathrm{TT} \uparrow, \Delta \mathrm{NT} \uparrow, \Delta \mathrm{IIT} \downarrow, \Delta \mathrm{GL} \downarrow$ & 3.4 & 4.4 & 1.2 & 1.4 & 10.4 \\
2 & $\Delta \mathrm{TT} \uparrow, \Delta \mathrm{NT} \uparrow, \Delta \mathrm{IIT} \uparrow, \Delta \mathrm{GL} \downarrow$ & 3.2 & 3.4 & 1.6 & 2.2 & 10.4 \\
3 & $\Delta \mathrm{TT} \uparrow, \Delta \mathrm{NT} \uparrow, \Delta \mathrm{IIT} \uparrow, \Delta \mathrm{GL} \uparrow$ & 2.0 & 3.8 & 0.6 & 1.4 & 7.8 \\
4 & $\Delta \mathrm{TT} \uparrow, \Delta \mathrm{NT} \downarrow, \Delta \mathrm{IIT} \uparrow, \Delta \mathrm{GL} \uparrow$ & 2.2 & 5.5 & 1.1 & 2.7 & 11.5 \\
5 & $\Delta \mathrm{TT} \downarrow, \Delta \mathrm{NT} \downarrow, \Delta \mathrm{IIT} \uparrow, \Delta \mathrm{GL} \uparrow$ & 1.8 & 7.9 & 0.8 & 2.1 & 12.6 \\
6 & $\Delta \mathrm{TT} \downarrow, \Delta \mathrm{NT} \downarrow, \Delta \mathrm{IIT} \downarrow, \Delta \mathrm{GL} \uparrow$ & 2.4 & 6.0 & 1.0 & 1.3 & 10.7 \\
7 & $\Delta \mathrm{TT} \downarrow, \Delta \mathrm{NT} \downarrow, \Delta \mathrm{IIT} \downarrow, \Delta \mathrm{GL} \downarrow$ & 3.0 & 7.4 & 1.9 & 3.2 & 15.5 \\
8 & $\Delta \mathrm{TT} \downarrow, \Delta \mathrm{NT} \uparrow, \Delta \mathrm{IIT} \downarrow, \Delta \mathrm{GL} \downarrow$ & 3.6 & 4.2 & 2.1 & 2.1 & 12 \\
& Total & 21.6 & 42.6 & 10.2 & 16.6 & 90.9 \\
9 & No trade in either period & 1.1 & & & & \\
10 & Total inter-industry trade & 7.9 & & & & \\
& Total & $100 \%$ of 2831 & & & \\
\hline
\end{tabular}

Source: OECD trade statistics and authors own calculations.

products allocated to each region. ${ }^{13}$

Any move involves an increase or decrease in total trade (DTT), net trade (DNT), intra-industry trade (DIIT) and the GL index (DGL). For example, it might be interesting to know how many of the products that increased imports and exports also revealed a fall in IIT and or the GL index or where the GL index and the value of IIT record opposite signs. Equally, one could illustrate how many products that the UK has moved from being a net exporter to a net importer and hence the UKs pattern of specialisation for any number of bilateral trade relationships across regions or individual countries.

Columns A to D represent the four possibilities for a movement from one trade point to another. From a total of 28315 -digit products, column A represents the percentage of cases where the UK is a net exporter in both periods. Likewise, column B shows the percentage of products where the UK has remained a net importer. The final two columns $\mathrm{C}$ and $\mathrm{D}$ represent therefore, the percentage of products not contained in columns A and B i.e. where the UK shifts from being either a net exporter to a net importer or visa versa.

In broad terms, between 1988 and 1997, rows one, two, three and four show that 40 percent of products with some two-way trade exhibit an increase in total trade

\footnotetext{
${ }^{13}$ Rows nine and ten pick up a number of anomalies in the trade data. For example, cases where there is no trade in one or both of the two periods or the export/import ratio is undefined because of zero trade values. Trade in row ten can be thought of as total inter-industry trade.
} 
( $\uparrow \Delta \mathrm{TT})$. This is coupled with rows two, three, four and five that show that 42.3 percent of products that show an increase in IIT $(\uparrow \Delta \mathrm{IIT})$. The SAH suggests that adjustment will be easier to facilitate in those industries. For the UK for example, if two consecutive trade points remain in the NE plane, an increase in net trade means that the sector is doing well in terms of its trade performance. Equally, if a product remains in the NI plane an increase in IIT will be advantageous as it means UK exporters have closed the gap between exports and imports. Although there are costs associated with a sector expanding the results of Table 2 reveals that relative to the rest of Europe that the UK economy may have performed better than expected.

From Section 1, when we look at the number of products where the GL index and absolute IIT levels have moved in opposite directions, rows two and six, we get a non-trivial total of over 21 percent (fifteen percent from Columns A and B represented by regions 2 and 6 in figure 6 and $6.1 \%$ from Columns $C$ and D represented by regions 2 and 6 in figure 7). This percentage implies that studies using the GL index as a dependent variable to reflect changes in IIT may be misleading if in over $21 \%$ of the cases the GL index and total IIT move in opposite directions. Figure 5 presents the percentage of trade-point movements that occur within each region of either the NE or NI planes, (columns A and B).

Examining the number of products in each region (that corresponds to rows one to eight and columns A and B in Table 2) allows us to visualise where potential problems may lie. For example, consider point $A$ where the UK is a net exporter and conceive of a move from $A$ to any other location in the NE plane. There are 61

Figure 6. UK products remaining in the Net Importer or Net Exporter Plane, 1988-1997

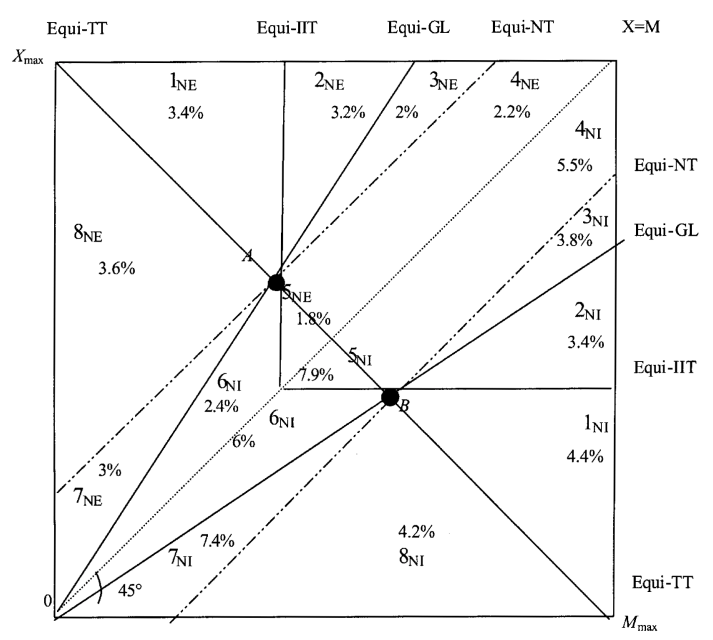


or $2.2 \%$ of SITC 5-digit products in region $4_{\mathrm{NE}}$ for example, where although total trade has increased, NT has fallen indicating that imports have increased more than exports exposing a potential unemployment problem (even if IIT and the GL index have risen). Of more concern, however, is the region $7 \mathrm{I}_{\mathrm{NE}}$ where TT, NT, IIT and the GL index all fall and contains 84 or 3\% percent of products. Not only has the total tradable market contracted but exports haven fallen by more than the decline in imports and IIT has decreased. ${ }^{14}$ The strength of this methodology is that we can simultaneously deduce the adjustment consequences for both trading partners and not rely solely on conclusions derived from general changes in IIT or GL values.

In relation to previous studies of IIT perhaps the most important observation is the large number of products that changed from a net import status to a net exporter or visa versa during the ten-year period. This has implications for the recent measures of marginal intra-industry trade (Brulhart 1994, Greenaway et al. 1994). Over 26 percent of products switched net trading position. Azhar et al. (1998) demonstrate that trade switching adversely effects the reliability of existing measures and as Table 2 and Figure 7 illustrate, the number of switches may be large enough to affect the robustness of the results. ${ }^{15}$

Finally, further pressures are revealed if we examine cases where trade flows switch planes (Columns $\mathrm{C}$ and D in Table 2). In Figure 7 the percentages in the NI

Figure 7. UK 5-digit products switching planes, 1988-1997

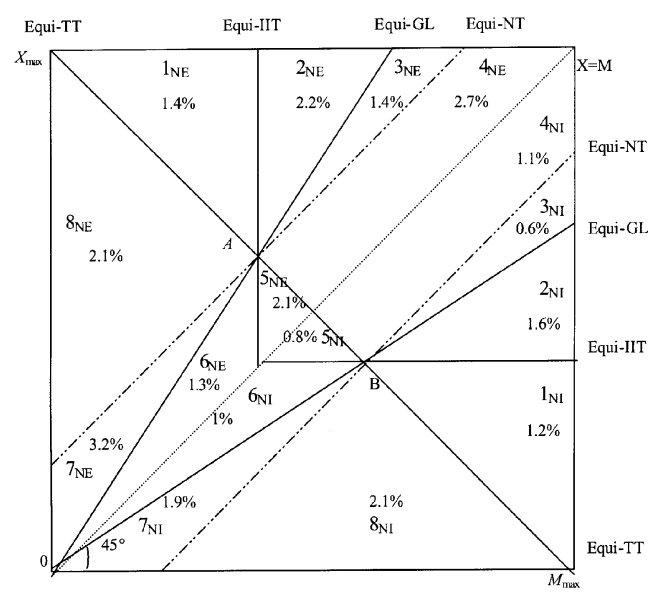

\footnotetext{
${ }^{14} \mathrm{~A}$ similar analysis can be done for those products then remain in the NI plane.

${ }^{15}$ At higher levels of aggregation the problem is not so severe. However, it is widely acknowledged in the trade literature that IIT should be measured at as lower level of aggregation as possible. See Greenaway and Milner (1986) and Finger (1975) for a discussion on categorical aggregation and IIT.
} 
plane represent products that were originally from the NE plane and visa versa.

The first observation from Figure 7 is that there are a larger number of products that switched from the NI to the NE plane (16.6 percent) against the number that moved from the NE to NI plane (10.2 percent) suggesting an improving export performance for the UK. Moreover, approximately 50 percent of those that switched did so as total trade fell suggesting that the UK maintained market share even during falling demand for that product.

Our conclusion is that the UK does not appear to have suffered adversely from increased competition due to greater European integration. Although beyond the scope of this paper, a closer examination of the product content of each region will provide an interesting insight into those sectors that are expanding and those that are contracting. These results can then be compared with employment and production figures to provide an overall picture of how well the UK is faring in the new Europe and where structural funds and regional aid should be allocated.

\section{Conclusions}

In this paper we employed a geometric tool to represent exports and imports as Cartesian co-ordinates in a square box. This enabled us to portray changes in trade patterns as movements in trade co-ordinates. The versatility of the methodology is emphasised by its applicability for any number of years or industries and for any bilateral or multilateral study of trade patterns. We show that care must be taken when employing the GL index in time series econometric studies. We suggest that there are a number of hypotheses in the international trade literature that could benefit from a fuller understanding of the relationship between the different trade components and how bilateral partners are effected in different ways by changes in trade flows. Specifically, the smooth adjustment hypothesis suggests that increases in intra-industry trade may result in a smoother reallocation of resources that inter-industry increases. This methodology allows us to accurately measure imports and exports and the relationship between total trade, net trade and intra-industry trade to reveal additional complexities in trade flows masked by existing empirical studies. In terms of the UKs experience of the European integration process we are able to say that the UK has performed better than many may have expected with its export share holding up even in declining markets. There remain a large number of alternative applications for this methodological approach yet to be exploited. 


\section{Acknowledgements}

The authors would like to thank without implication, an anonymous referee, Chris Milner, Peter Dixon and Matthew Cole for useful comments and suggestions and to participants at the ETSG Rotterdam.

Economic Integration and the Evolution of Trade: A Geometric Interpretation of Trade Measures.

Received 21 January 2003, Accepted 8 July 2003

\section{References}

Azhar, A.K.M., Elliott, R.J.R., and Milner, C.R. (1998), Static and Dynamic Measurement of Intra-industry Trade and Adjustment: A Geometric Reappraisal. Weltwirtschaftliches Archiv, 134, 404-422.

Azhar, A.K.M. and Elliott, R.J.R. (2003), On the Measurement of Trade Induced Adjustment, Weltwirtschaftliches Archiv, (Vol. 139, no.3, pp. 419-439).

Balassa, (1966) Tariff Reductions and Trade in Manufactures Among the Industrial Countries. American Economic Review, vol. 56, pg. 466-473.

Bernhofen, D (1999) Intra-Industry Trade and Strategic Interaction: Theory and Evidence. Journal of International Economics, Vol. 47, pg. 225-244.

Brülhart, M. (1994), Marginal Intra-industry Trade: Measurement and Relevance for the Pattern of Industrial Adjustment. Wetwirtschaftliches Archiv, 130, 600-613.

Brülhart, M. and Hine, R.C. (1999) Intra industry Trade and Industrial Adjustment: The European Experience. London. Macmillan

Davis, D. (1995) Intra-Industry Trade: a Heckscher-Ohlin-Ricardo Approach. Journal of International Economics, 39: 3-4.

Dixon, P. and Menon, J. (1997), Measures of Intra-industry Trade as Indicators of Factor Market Disruption. Economic Record, 73, 233-237

Falvey, R. (1981), Commercial Policies and Intra-industry Trade, Journal of International Economics, 11, 495-511.

Greenaway, D. and Milner, C.R. (1986), The Economics of Intra-Industry Trade. Basil Blackwell. Oxford.

Greenaway, D., Hine, R.C., Milner, C.R. and Elliott. R.J.R. (1994), Adjustment and the Measurement of Marginal Intra-Industry Trade. Weltwirtschaftliches Archiv 130(2): 418-427.

Greenaway, D., Hine, R.C. and Milner, C.R. (1995), Vertical and Horizontal Intra-Industry Trade: A Cross Industry Analysis for the United Kingdom. Economic Journal, 105, 1505-1519.

Grubel, H. and Lloyd, P. (1975), Intra-Industry Trade. London, Macmillan. 
Hamilton, C. and Kniest, P. (1991). Trade Liberalisation, Structural Adjustment and IntraIndustry Trade. Weltwirtschaftliches Archiv, 127, 356-367.

Helpman, E. (1987) Imperfect Competition and International Trade: Evidence From Fourteen Industrial Countries. Journal of Japanese and International Economies, 1, 62-81.

Hummels, D and Levinsohn, J (1995), Monopolistic Competition and International Trade: Reconsidering The Evidence, Quarterly Journal of Economics, 110, 799-836.

Krugman, P. R. (1979), Increasing Returns, Monopolistic Competition, and International Trade. Journal of International Economics, 9, 469-79.

Krugman, P.R. (1987), Economic Integration in Europe: Some Conceptual Issues. Reprinted in Jacquemin, A. and Sapir, S. (eds) (1989) The European Internal Market, Oxford: Oxford University Press.

Lancaster, K (1980), Intra-industry Trade under Perfect Monopolistic Competition. Journal of International Economics, 10(2), 151-175. 